Book reviews

\section{Medicine, Health and Justice: the problem of priorities}

\section{Alastair V Campbell \\ Edinburgh, London and New York. Churchill Livingstone, 1978.}

Auden said of Freud that, in spite of his errors and absurdities, he was no longer a person, he had become a climate of opinion. This, or something like it, is true of the post-1974 Health Service. In spite of all the difficulties which it has encountered and which are now under consideration by a Royal Commission, the reorganised NHS has undoubtedly engendered a new climate of opinion about health care and, in particular, about priorities in health care.

Today, we are no longer satisfied with narrow, managerial, or technocratic criteria. However valuable as aids to discussion, cost benefit analysis and cost effectiveness analysis, which were beginning to exercise an almost hypnotic influence on health priorities, would no longer be considered adequate to cope with the complexities of the situation. In other words, the economic rationality and technological determinism, which dominated the Health Service after the Guillebaud Committee had concluded that escalating costs could be contained only through an increase in managerial efficiency, have now given way to a consideration of the 'longer, broader and deeper' issues involved. Today, as Aaron Wildavsky never tires of pointing out, economic rationality has to be supplemented by political rationality; and Dr Campbell's book would not have been written if he did not believe that both have to be rooted in ethical rationality.

In the light of this transformation in our approach to health care problems, Medicine, Health and fustice could not have been published at a more opportune moment. Because of the emphasis of contemporary society on hard science, it has generally been assumed that ethical values cannot be discussed in rational terms. Values, indeed, have been regarded as the irrational element in decision-making, which the true scientist should either eliminate or try to reduce to the minimum. But, if medicine is an art making use of science, as Osler claimed, it would be less perverse on our part (since values would have primacy in such a philosophy of health care) if we were to use science and reason to illuminate the ethical dimension of decision-making.

For any exploration of a new and uncharted terrain we need a map, on which at least the main features of that terrain have been delineated. In this book Dr Campbell has provided us with such a map. As a concise way of identifying the main ethical considerations involved, he goes back to the three great watchwords of the French Revolution, namely, liberty, equality and fraternity - the greatest of these, Dr Campbell would claim, being fraternity.

Although the significance of 'social cohesiveness' is implicit, rather than explicit, in this book, it is not a position at which $\mathrm{Dr}$ Campbell has arrived lightly. On the contrary, his study largely consists of a lucid exposition of Locke's Social Contract, of the Hobbesian doctrine of Sovereignty, of Kant's Categorical Imperative, of Rousseau's General Will and of the different forms of Utilitarianism espoused by Bentham, Mill and Sidgwick - with the main themes of his analysis being brought together in a final exposition and critique of Rawls' massive $A$ Theory of fustice. Interwoven with this philosophical discussion are pointed comparative descriptions (which do not pretend to be other than illustrative) of specific aspects of the health care systems of America, the United Kingdom, China and Russia.

Dr Campbell's explicit thesis is that ethical considerations can be given full weight only if liberty, equality and fraternity are so synthesised that they exist in 'creative tension'. If we push liberty too far, the costs in terms of sociait justice become insupportable. If we push equality too far, the costs in terms of freedom, or autonomy (2) concept which Dr Campbell equate with health) become intolerable in their turn. Nor is 'equal freedomiv quite enough either; and Rawlso view that inequality is justified when it helps the most disadvantaged members of society, is suspect as being merely a highly sophisticate formulation of traditional liberas philosophy. Dr Campbell is sym $\stackrel{\Phi}{=}$ pathetic to the Marxian concept of the social individual; and he would no doubt agree with $\mathrm{G} H$ Mead that we become ourselves, and achiev $\$$ our identities, not at the expense of but through, our fellows. What we need, perhaps, is a new ethicad paradigm based on concepts of co尺 operation and mutual aid, with liberty and equality (in the sense of equity) finding their own level withing that new framework. Given competitive, or market, model of society, liberty will always be at odds with equality, and, except fo cosmetic reasons, neither will havé any use for fraternity. Indeed, given such a model, the notion that men? in Alvin Gouldner's graphic phrase, must remain divided against each other (whether on the side of liberty or of equality) until the end of times will be perpetuated.

Dr Campbell would not claim for his book that it is anything more than one of many possible starting points for an exploration in depth of the ethical issues which arise in the field of health priorities. It was a shrewd stroke, however, to base hi@ particular starting point on an overview of the positions of the great ${ }^{-}$ classical philosophers ('off whom', as T Wright Mills once said, 'we are stilp living'), and on an exposition of the central tenets of one of the fewoD contemporary philosophers who, in the comprehensiveness and rigour of his approach, might be thought, in this field, to rank with his eminento 
predecessors. This has given the author's map of the ethical world a lasting value; but, not only does this book have behind it the impetus of three centuries of philosophy, it also has an authority unique to itself because of Dr Campbell's resolute refusal to countenance the possibility of some all-embracing ethical formula based on a purely logical amalgam, or aggregation, of the best aspects of liberty, equality and fraternity. Given that situations differ in space and in time, such an amalgam or aggregation, could never have been more than an exercise in academic futility - except, of course, to the extent that the search for a formula is always the search for an authoritarian, or 'managerial', solution.

Men must decide their own destiny; and this book makes it clear that there is no alternative to a procedure which allows for, and encourages, the rich interplay of different perspectives.

To this end, Dr Campbell proposes Peter Berger-type 'intermediate structures', through which would be mediated, not alienation, but participation, involvement and the positive growth of human potential.

This anti-authoritarian stance goes well with the author's sympathetic approach to the existentialist aspects of Marxism. Donne said that sickness was 'loss of self', and the way in which Dr Campbell correlates health with autonomy (which is 'freedom for' rather than 'freedom from') while at the same time substituting the language of 'shared aspirations' for the language of 'individual gain', makes me a little regretful that he has not been able to bring the existentialist position more fully into the reckoning.

Notoriously ambivalent about liberty, equality and fraternity - and subscribing to their own particular 'Trinity' - the existentialist philosophers are primarily concerned with man's awesome responsibility to make the hard and painful choices through which he can at last begin to shape his own future. From this point of view, it may not simply be a question of moving resources sideways from the acute sector to the long-term one - a shift of emphasis which would be regarded in a favourable light by Dr Campbell (but which is not without its difficulties since the elderly themselves are now exerting increasing pressure on the acute facilities). Instead, it may actually be a question of moving resources, over time, from both of these sectors into the immensely difficult areas of prevention and health-promotion, with funds being committed outwith the health service altogether eg to housing, employment, social work etc., and with the notion of the 'community itself as doctor' being ever more actively fostered. How to effect this vast shift from a disease service to a health service, and from a health service to a healthy society - that, too, is an ethical question of the first order of magnitude.

DRUMMOND HUNTER

\section{Reasoning about madness}

\section{$\mathrm{J} \mathrm{K}$ Wing}

Oxford University Press, 1978, pp $256 £ 3.50$

In reading this book one cannot but admire the breadth of the approach with which Professor Wing addresses his subject. Unfortunately the book suffers somewhat from this very quality. Allowing for the demands of size, the selection of theories reviewed must inevitably be restricted and thus we come to realise the author's personal view quite definitely. Having said this I was still impressed by its range. In particular, the chapters on schizophrenia and on psychiatry and political dissent are well worth attention. Both chapters reflect the author's unflagging curiosity and scholarship and give the uninitiated a glimpse into the topic, sufficient to make him look further.

The chapters on the history of the development of Mental Hospitals and Service and legal structures associated are very weak. I suspect that this occurs as the book very much reflects Professor Wing's London and Institutive Psychiatry bias in recent years. Having myself spent many years working North of the Border I feel he missed the immense influence the Scottish scene has had on psychiatry in this country. The Scottish legal scene was always different from England so that patients were admitted voluntarily and doors were open much in advance of South of the Border. In addition the Mental Welfare Commission's role, in being the patient's ombudsman, has now undoubtedly been proved as far excelling that of the Mental Health Tribunals and some detail with regard to this would have been helpful. In the field of care the influence of the Social Psychiatrist is I feel inadequately dealt with in the book though this may be my personal bias. Maxwell Jones' contribution to psychiatry is much wider than the Henderson Hospital - he revolutionised the idea of the Area Service at Dingleton Hospital, Melrose one does not have to go to Leningrad as Professor Wing did to see a Community Care Service which encompasses client and family support, 24-hour Acute Service and Shelter. Also in the concept of secondary prevention I consider the work of the people at Napsbury Hospital with their crisis intervention unit should be seen as a growth point. Maybe a psychiatrist with a more personal experience rather than metropolitan would have seen things a little different.

Despite my critical reactions I would recommend this book to the interested lay person and the committed professional. Professor Wing will teach both a lot. He has gone into this subject with a very wide over view. In addition I was impressed at the author's obvious enthusiasm and felt positively held and excited by the process of discovery as he related it.

J V BASSON 